\title{
Iron and callose homeostatic regulation in rice roots under low phosphorus
}

\author{
Yan Ding ${ }^{1,3}$, Zegang Wang ${ }^{2}$, Menglian Ren², Ping Zhang ${ }^{2}$, Zhongnan $\mathrm{Li}^{2}$, Sheng Chen ${ }^{2}$, Cailin $\mathrm{Ge}^{2^{*}}$ \\ and Yulong Wang ${ }^{1 *}$
}

\begin{abstract}
Background: Phosphorus (Pi) deficiency induces root morphological remodeling in plants. The primary root length of rice increased under Pi deficiency stress; however, the underlying mechanism is not well understood. In this study, transcriptome analysis (RNA-seq) and Real-time quantitative PCR (qRT-PCR) techniques were combined with the determination of physiological and biochemical indexes to research the regulation mechanisms of iron (Fe) accumulation and callose deposition in rice roots, to illuminate the relationship between Fe accumulation and primary root growth under Pi deficient conditions.

Results: Induced expression of LPR1 genes was observed under low Pi, which also caused Fe accumulation, resulting in iron plaque formation on the root surface in rice; however, in contrast to Arabidopsis, low Pi promoted primary root lengthening in rice. This might be due to Fe accumulation and callose deposition being still appropriately regulated under low Pi. The down-regulated expression of Fe-uptake-related key genes (including IRT, NAS, NAAT, YSLS, OsNRAMP1, ZIPS, ARF, and Rabs) inhibited iron uptake pathways I, II, and III in rice roots under low Pi conditions. In contrast, due to the up-regulated expression of the VITs gene, Fe was increasingly stored in both root vacuoles and cell walls. Furthermore, due to induced expression and increased activity of $\beta-1-3$ glucanase, callose deposition was more controlled in low Pi treated rice roots. In addition, low Pi and low Fe treatment still caused primary root lengthening.
\end{abstract}

Conclusions: The obtained results indicate that Low phosphorus induces iron and callose homeostatic regulation in rice roots. Because of the Fe homeostatic regulation, Fe plays a small role in rice root morphological remodeling under low Pi.

Keywords: Rice (Oryza sativa), Low phosphorus, Iron homeostasis, Root morphology

\section{Background}

Plant root morphology is regulated by numerous factors, such as water and nutrient availability. Phosphorus (Pi) and iron $(\mathrm{Fe})$ have been reported to influence the plant root length. In Arabidopsis, it has been proposed that Pi deficiency inhibits the root apical meristem (RAM) activity due to increased Fe bioavailability and its associated cellular toxicity [1].

The remodeling mechanism has been reported for Arabidopsis on root morphology in low Pi. Multicopper

\footnotetext{
* Correspondence: clge@yzu.edu.cn; ylwang@yzu.edu.cn

${ }^{2}$ College of Bioscience and Biotechnology, Yangzhou University, 88 Daxue

South Road, Yangzhou 225009, People's Republic of China

${ }^{1}$ Jiangsu Key Laboratory of Crop Genetics and Physiology/ Jiangsu Key Laboratory of Crop Cultivation and Physiology, Jiangsu Co-Innovation Center for Modern Production Technology of Grain Crops, Agricultural College of Yangzhou University, Yangzhou University, 88 Daxue South Road, Yangzhou 225009, People's Republic of China

Full list of author information is available at the end of the article
}

oxidase, Low Phosphate Root 1 (LPR1) is necessary for root growth inhibition caused by Pi limitation in Arabidopsis. A common pathway combining with LPR2 and PHOSPHATE DEFICIENCY RESPONSE 2 (PDR2) adjusts root meristem activity and phosphate availability [2-4]. In Arabidopsis under low $\mathrm{Pi}$, the sites of iron (Fe) accumulation and callose deposition are determined by the LPR1-PDR2 modules in both the meristem and elongation zone of the primary root, via apoplastically located LPR1 activity. Callose deposition, which causes impaired movement of SHORT ROOT (SHR) and interferes with the symplastic communication, is responsible for root meristem differentiation [5]. Low Pi stress induces iron mobilization in RAM through the action of $L P R 1 / L P R 2$, causing the expression of CLAVATA3/ENDOSPERM SURROUNDING REGION (CLE14) in the proximal meristem region. CLAVATA2 (CLV2) and PEP1 RECEPTOR 2 (PEPR2) receptors perceive CLE14 and trigger RAM

(c) The Author(s). 2018 Open Access This article is distributed under the terms of the Creative Commons Attribution 4.0 International License (http://creativecommons.org/licenses/by/4.0/), which permits unrestricted use, distribution, and 
differentiation in Arabidopsis, with concomitant down-regulation of both SHORT ROOT (SHR)/SCARECROW (SCR) and PIN/AUXIN pathways [6].

Recently, researchers increasingly focused on the mechanism underlying the rice response to low Pi. Pi deficiency causes a significant reduction in the net photosynthetic rate of rice plants [7]. Photosynthetic $\mathrm{CO}_{2}$ assimilation is decreased by $\mathrm{Pi}$ deficiency as a result of the decreased RuBP pool size in rice [8]. Pi deficiency affects diverse metabolic pathways most of which are related to glucose, pyruvate, sucrose, starch, and chlorophyll a in rice leaves [9]. The genes involved in Pi transport, phosphatases, and genes pertaining to both primary and secondary metabolism were affected differently by Pi deficiency in rice roots [10]. Phosphate over accumulator 2 (OsPHO2) knockout mutants indicates that OsPHO2, which functions downstream of the phosphate transporter traffic facilitator 1 (OsPHF1), modulates $\mathrm{Pi}$ utilization by regulating the expression of Pht1 transporters in rice [11]. The Phosphate Starvation Response Regulator 1 (PHR1) is a MYB transcription factor that plays a key role in Pi starvation signaling. OsPHR1 and OsPHR2 are homologous proteins of PHR1 in rice [12]. Overexpression of OsPHR2 in rice mimicked the Pi starvation signal. It induces Pi Starvation Induced (PSI), OsIPS1/2 (the gene encoding the signal molecules), miRNAs, SPX domain-containing protein (SPXs), phosphate transporter (PTs), and purple acid phosphatases (PAPs) gene expression, and results in enhanced Pi acquisition [12-17].

Root elongation induced by $\mathrm{Pi}$ deficiency has been reported as one of the adaptive mechanisms in plants. Enhanced external root efficiency or root growth may result in high phosphorus uptake from Pi-deficient soils. About $90 \%$ of Pi uptake was found as the result of enhanced root growth per unit root size in rice [18]. Studies have illustrated the inhibition of plant height, total dry weight, shoot dry weight, and root number under Pi deficiency, but the maximum yields of root length and root-shoot ratio were achieved by $\mathrm{Pi}$-deficiency stress in rice [19]. A significant root elongation was indeed induced in rice under Pi-deficient conditions [20]. Root elongation clearly varied among different rice varieties screened under two different Pi levels [20, 21]. Genetic differences were found in rice root elongation under $\mathrm{Pi}$ deficiency, and a distinct quantitative trait locus (QTL) was reported on the long arm of chromosome 6 [22]. In addition, this QTL itself, or a tightly linked region, partly explains the decreased ability of excess iron accumulation in the shoots. The identified QTL would be useful in the improvement of rice varieties overcoming complex nutritional disorder caused by both Pi deficiency and iron-excess toxicity [20]. In the rice reference genome, as well as other phosphorus-starvation-intolerant modern varieties, phosphorus-starvation tolerance 1 (PSTOL1) was absent [23]. PSTOL1 also played a role as an enhancer in early root-growth, thus enabling plants to acquire more phosphorus and other nutrients. In such varieties, overexpression of PSTOL1 significantly enhanced grain production in phosphorus-deficient soil [24]. Overexpression of OsPHR2 led to Pi accumulation in rice leaves, as well as increases in root length, root-shoot ratio, and the number of root hairs [12]. Currently, OsWRKY74 is the unique confirmed WRKY gene which involved in the regulation of phosphate starvation response in rice. Transgenic seedlings overexpressing OsWRKY74 improved Pi uptake, length of roots, biomass, and iron accumulation levels, indicating that OsWRKY74 may be involved in the coordinate regulation of iron and Pi uptake [25].

Interestingly, $\mathrm{Pi}$ starvation induces the formation of reddish brown iron plaques on the surface of rice roots $[26,27]$, further promoting Fe accumulation in roots and shoots of rice plants [28]. However, the primary root and lateral root lengths both increase noticeably in tolerant rice cultivars under low $\mathrm{Pi}$ conditions [29]. This result suggests a different mechanism for the rice root morphological remodeling response to Pi deficiency compared to Arabidopsis. To date, the root morphological remodeling mechanism under low $\mathrm{Pi}$ in rice still remains unclear.

To illuminate whether Fe plays an important role in the regulation of rice root lengths under low $\mathrm{Pi}$, the primary root length, Fe accumulation, and callose deposition in (or on) rice roots were investigated. Furthermore, Fe uptake, Fe distribution, and callose degradation-related gene expression were analyzed under low Pi conditions.

\section{Results}

\section{Low pi led to root lengthening in rice}

The effect of low Pi treatment (1/25 of a normal Pi supply level) on primary rice root length is shown in Table 1 . Compared to the control (normal Pi supply level), the primary root length of rice cultivars Tongjing981 (TJ981) and ZhenDao 99 (ZD99) increased significantly $(P<0.05$ and $P<0.01$, respectively) after seedlings were treated in low Pi for 7, 15, and $30 \mathrm{~d}$. However, primary root length

Table 1 Root length affected by low Pi treatment for 7, 15, 30 days

\begin{tabular}{lllll}
\hline Samples & & \multicolumn{3}{l}{ Treatment time(d) } \\
\cline { 3 - 5 } & & 7 & 15 & 30 \\
\hline TJ981 & Normal P & $8.40 \pm 0.60$ & $11.65 \pm 0.37$ & $24.77 \pm 1.09$ \\
& Low P & $9.73 \pm 0.63^{* *}$ & $13.98 \pm 0.61^{* *}$ & $42.15 \pm 2.73^{* *}$ \\
ZH6 & Normal P & $6.83 \pm 0.24$ & $10.43 \pm 0.46$ & $22.23 \pm 1.24$ \\
& Low P & $7.09 \pm 0.28$ & $9.54 \pm 0.56$ & $31.93 \pm 2.25^{* *}$ \\
ZD99 & Normal P & $7.14 \pm 0.31$ & $9.45 \pm 0.47$ & $25.46 \pm 1.20$ \\
& Low P & $7.67 \pm 0.38^{* *}$ & $11.18 \pm 0.99^{* *}$ & $39.38 \pm 2.53^{* *}$
\end{tabular}

"**" and "***" represent significant $(P \leq 0.05)$ and very significant difference $(P \leq 0.01)$ compared to control (the same applies hereinafter) 
change in ZhengHan 6 (ZH6) was either not significant (at $7 \mathrm{~d}$ ) or significantly reduced (at $15 \mathrm{~d}$ ); primary root length increased significantly when treated at low Pi for $30 \mathrm{~d}$. These results indicate that low Pi stress promoted rice primary root lengthening, which is one of the main strategies of most rice cultivars to achieve acclimation to Pi deficiency. Apparently, the response pattern in root lengthening varied among different cultivars.

\section{Low pi promoted iron plaque formation on the rice root surface}

DCB-Fe is the adsorption or precipitation of iron on the root surface. Consequently, a reddish-brown iron plaque on the rice root surface began to form after treatment by low Pi for 1d (Fig. 1a), and the thickness of iron plaque continuously increased with the prolonging of low $\mathrm{Pi}$ treatment time (Fig. 1b and c). The DCB-Fe contents increased either significantly or very significantly (Fig. 2) under the low Pi treatment for $15 \mathrm{~d}$. Fe deposition on the rice root surface under low Pi treatment was confirmed by our results.

\section{Low pi induced LPR1 genes expression}

In Arabidopsis, the LPR1-PDR2 module mediates cellspecific Fe deposition in the cell walls of the RAM and elongation zone during $\mathrm{Pi}$ limitation. This provides evidence for apoplastic LPR1 ferroxidase activity and suggests that antagonistic interactions of $\mathrm{Pi}$ and $\mathrm{Fe}$ availability adjust the primary root growth rate via RAMspecific callose deposition, which is likely triggered by LPR1-dependent redox signaling [5]. In this experiment, the results of transcriptome sequencing showed that the expression of multicopper oxidase LPR1 homolog 1-5 genes in the roots of three tested varieties was induced by low $\mathrm{Pi}$ treatment for $15 \mathrm{~d}$ (Table 2). Furthermore, the results of proteomic detection showed that the content of the LPR1 protein in low Pi treated rice roots was higher than that in the roots of control (data not shown). This suggests that the formation of Fe plaques on rice root surface was promoted by the induction of LPR1 gene expression.

\section{Low pi increased Fe content in the rice root symplast} Due to Fe deposition on the root surface, the Fe content increased very significantly in the root symplast of the three tested rice cultivars compared to the control (Fig. 3). It is interesting that the increased degree of Fe content in the root symplast was substantially lower than that deposited on the root surface. For example, in ZH6 cultivar Fe content on low Pi treated root surface increased by $7.77 \mathrm{mg}$ compared to control (Fig. 2); however, it only increased by $0.19 \mathrm{mg}$ in the ZH6 root symplast (Fig. 3). This result suggests that Fe uptake by the rice root symplasm might be limited under low Pi stress.

\section{Regulation of Fe accumulation in rice root symplasts} under low pi stress

Gene expression regulation

Differential expression of Fe uptake related genes detected via transcriptome sequencing The results basically clarified the existence of two distinct high affinity iron transport mechanisms in plants [30]. Non-graminaceous monocots and all dicots use the mechanism I Fe uptake strategy, while grasses use the mechanism II strategy. As a special case, rice may utilize both mechanism I and II Fe uptake strategies [31].

These experimental results indicate that the Fe uptake of mechanisms I and II was entirely inhibited by down regulating the expression of key enzyme encoding genes, associated with $\mathrm{Fe}$ uptake in rice roots under low $\mathrm{Pi}$ (Table 3).

Although the expression of a ferric reductase transmembrane protein (FR) gene (OS09G0500900) in the ZH6 root was induced by low $\mathrm{Pi}$, the expression of the $\mathrm{Fe}^{2+}$ transport protein 2 gene (IRT, OS03G0667300) was inhibited by low $\mathrm{Pi}$ in all three tested cultivars (Table 3),

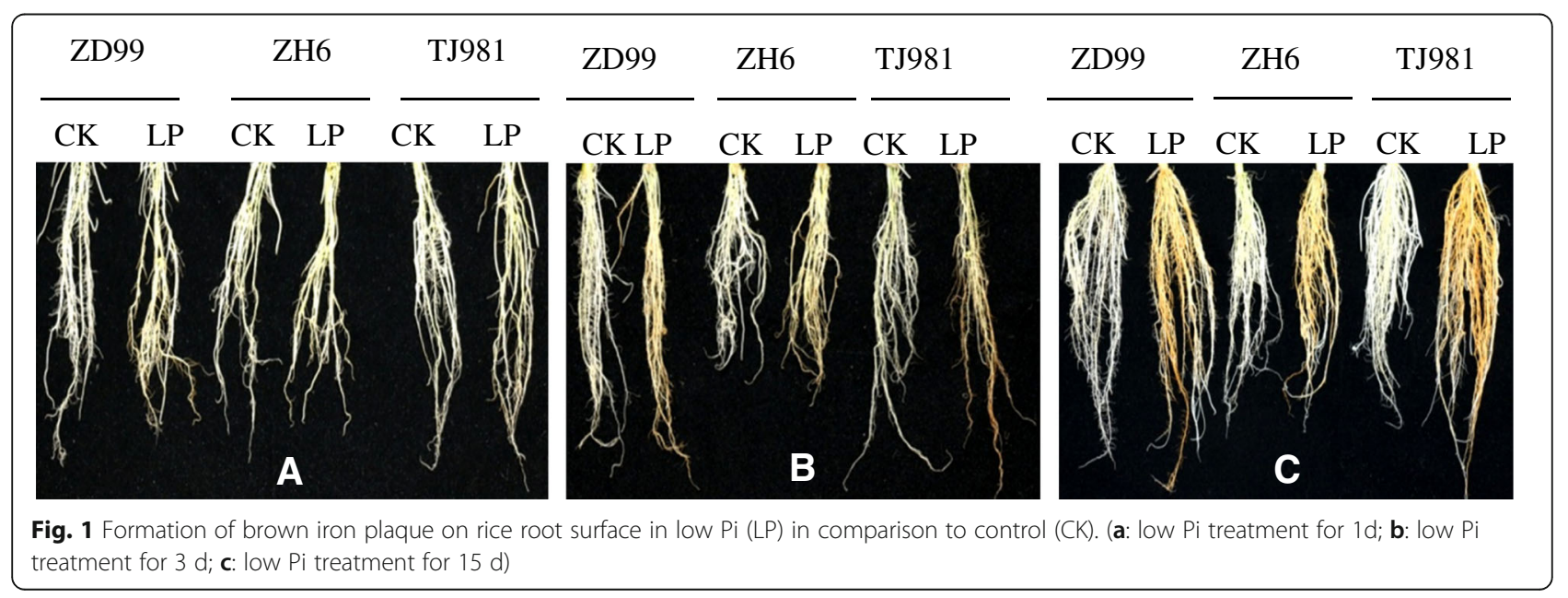




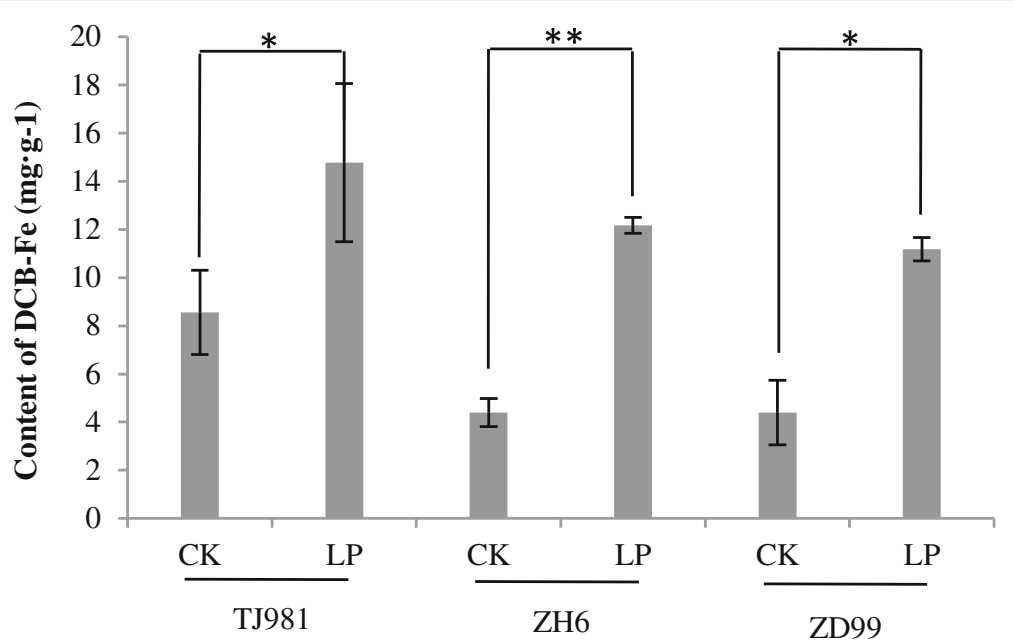

Fig. 2 DCB-Fe content on root surface under low Pi treatment for $15 \mathrm{~d}$. Notes: ${ }^{*}$ indicates significant difference $(P \leq 0.05),{ }^{* *}$ indicates extremely significant difference $(P \leq 0.01)$

suggesting that low Pi reduced $\mathrm{Fe}^{2+}$ uptake by rice roots. Furthermore, the expression of nicotianaminesynthase (NA2, OS03G0307200; NA1, OSO3G0307300) and nicotianamine aminotransferase A (NAAT, OS02G0306401) was down-regulated under low $\mathrm{Pi}$ (Table 3), showing that low Pi inhibited PS biosynthesis. Moreover, the expression of an ADP-ribosylation factor (such as ARF1, OS03G0811900; ARF2, OS01G0265100) and Rab GTPases (such as RABA1f, OS01G0667600; RABA5c, OS08G0525000; RABA2a, OS03G0843100) was downregulated under low $\mathrm{Pi}$ (Table 3 ), suggesting that low $\mathrm{Pi}$ inhibited PS secretion. Furthermore, the expression of the Fe or metal-phytosiderophore transporter (YSL15, OSO2G0650300; YSL2, OS02G0649900; YSL9,OS04G 0542200) was all down-regulated due to low Pi (Table 3), indicating that low $\mathrm{Pi}$ also inhibited $\mathrm{Fe}^{3+}$-PS complex transportation.

Additionally, plants might also utilize a mechanism III iron absorption strategy. Moil (1999) reported that the metal transporter Nramp played an important role in the absorption of iron and other metal ions and suggested that plants may use a novel mechanism for phagocytic iron absorption. In this mechanism, Nramp can release $\mathrm{Fe}^{2+}$ from the endosome, then transferring it to the cytoplasm. Table 3 shows that low Pi down-regulated the expression of metal transporter Nramp1 (NRAMP1, OSO7G0258400), indicating that the phagocytic mechanism of $\mathrm{Fe}^{2+}$ uptake is also inhibited by low Pi.

It is worth noting that the expression of the vacuolar iron transporter 2 gene (VIT2, OSO4G0538400) and vacuolar iron transporter 1.2 (VIT1.2, OS09G0396900) was strongly induced by low Pi stress (Table 3), which suggests that the distribution of $\mathrm{Fe}$ in root cells was probably regulated by the expression of low-Pi-responsive genes.

\section{The transcriptional level of differentially expressed genes verified via $q R T-P C R$}

To verify the transcriptome sequencing results, nine differentially expressed genes were selected and their transcriptional levels were tested via real-time fluorescent quantitative PCR (qRT-PCR) after rice seedlings were treated by low Pi for $15 \mathrm{~d}$. The results (Fig. 4) show that the transcription of NA2, NAAT, YSL15, YSL2, YSL9, NRAMP1, ZIP, and RABA2a were down-regulated; however, the transcription of VIT2 was up-regulated, which fully agrees with the results of transcriptome sequencing.

Table 2 The expression induction of LPR1 genes in rice roots treated by low Pi for $15 \mathrm{~d}$

\begin{tabular}{|c|c|c|c|c|}
\hline \multirow[t]{2}{*}{ gene } & \multirow[t]{2}{*}{ Description } & \multicolumn{3}{|l|}{$\log 2 \mathrm{FC}$} \\
\hline & & TJ981 & ZD99 & $\mathrm{ZH} 6$ \\
\hline OS01G0126100 & Multicopper oxidase LPR1 homolog 1 & $1.274^{* *}$ & $1.267^{* *}$ & $1.036^{* *}$ \\
\hline OS01G0126200 & Multicopper oxidase LPR1 homolog 2 & $1.134^{*}$ & 0.550 & $1.305^{*}$ \\
\hline OS01G0127000 & Multicopper oxidase LPR1 homolog 3 & $6.078^{* *}$ & $2.453^{* *}$ & $2.496^{*}$ \\
\hline OSO1G0126900 & Multicopper oxidase LPR1 homolog 4 & $2.055^{* *}$ & $1.405^{* *}$ & 0.275 \\
\hline OS01G0127200 & Multicopper oxidase LPR1 homolog 5 & $2.180^{*}$ & $1.740^{* *}$ & 1.153 \\
\hline
\end{tabular}

Notes: ${ }^{*}$ indicating the difference significant $(P \leq 0.05),{ }^{*}$ indicating the difference extremely significant $(P \leq 0.01)$. The expression fold change $(\mathrm{LP} / \mathrm{ck}) \mathrm{FC}=2^{\mathrm{Log} 2 \mathrm{FC}}$ 


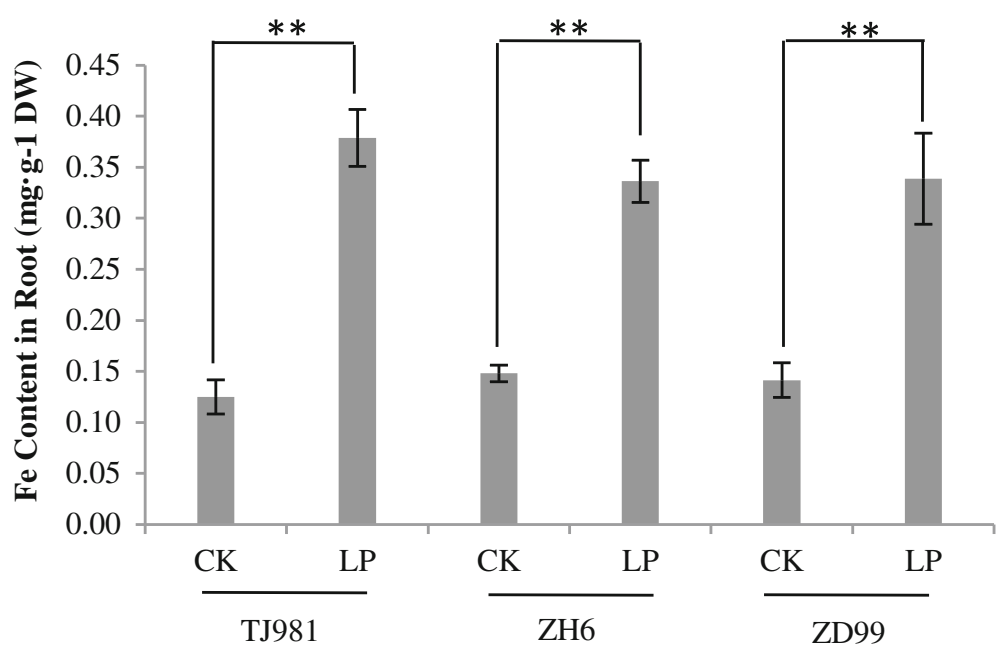

Fig. 3 Effect of low Pi treatment on iron content in rice roots. Notes: ${ }^{* *}$ indicates extremely significant difference $(P \leq 0.01)$

Effect of low pi and treatment time on the transcriptional level of key differentially expressed genes

Four key genes associated with $\mathrm{Fe}^{3+}$ uptake (NA2, NAAT, and YSL15) and intracellular distribution (VIT2) were selected to determine the effect of low Pi treatment time on the resulting transcriptional level. The results showed that the transcriptional levels of NA2, NAAT, and YSL15 were inhibited by low $\mathrm{Pi}$, and that inhibition of their transcription began after low Pi treatment for only $1 \mathrm{~d}$. The transcriptionally inhibited degree of NA2 increased with the prolonging of low Pi treatment time. However, the inhibited degree of NAAT and YSL15 decreased slightly due to low Pi treatment for $5 \mathrm{~d}$ or $9 \mathrm{~d}$; therefore, the first five days after low Pi treatment may form an emergency response stage; then, the inhibited degree increased again with low $\mathrm{Pi}$ treatment time further

Table 3 Effect of low Pi on transcriptional level of the iron absorption related genes detected via illumina expression profile sequencing

\begin{tabular}{|c|c|c|c|c|c|c|c|}
\hline \multirow[t]{2}{*}{ Ensemble_id } & \multirow[t]{2}{*}{ Description } & \multicolumn{2}{|l|}{ TJ981 } & \multicolumn{2}{|l|}{$\mathrm{ZH} 6$} & \multicolumn{2}{|l|}{ ZD99 } \\
\hline & & $\log _{2} \mathrm{FC}$ & $\overline{P \text {-Value }}$ & $\log _{2} \mathrm{FC}$ & $P$-Value & $\log _{2} \mathrm{FC}$ & $P$-Value \\
\hline OS03G0667300 & $\mathrm{Fe}^{2+}$ transport protein $2(\mathrm{IRT})$ & -2.683 & 5.00E-05 & -3.766 & $5.00 \mathrm{E}-05$ & -2.082 & 0.0003 \\
\hline OS03G0307200 & Nicotianamine synthase 2 (NA2) & -2.731 & 5.00E-05 & -5.639 & 5.00E-05 & -2.353 & $5.00 \mathrm{E}-05$ \\
\hline OS03G0307300 & Nicotianamine synthase 1 (NA1) & -2.722 & 5.00E-05 & -5.612 & $5.00 \mathrm{E}-05$ & -2.433 & 5.00E-05 \\
\hline OS02G0306401 & Nicotianamine aminotransferase (NAAT) & -2.817 & 5.00E-05 & -5.166 & 5.00E-05 & -2.813 & 5.00E-05 \\
\hline OS02G0650300 & Iron-phytosiderophore transporter (YSL15) & -2.474 & 5.00E-05 & -4.732 & $5.00 \mathrm{E}-05$ & -2.695 & $5.00 \mathrm{E}-05$ \\
\hline OS02G0649900 & Metal-nicotianamine transporter (YSL2) & -4.446 & $5.00 \mathrm{E}-05$ & -4.201 & $5.00 \mathrm{E}-05$ & -2.774 & $5.00 \mathrm{E}-05$ \\
\hline OS04G0542200 & Probable metal-nicotianamine transporter (YSL9) & -1.485 & 5.00E-05 & -1.419 & $5.00 \mathrm{E}-05$ & -0.694 & - \\
\hline OSO7G0258400 & Metal transporter Nramp1 (OsNRAMP1) & -2.134 & 5.00E-05 & -3.658 & $5.00 \mathrm{E}-05$ & -2.479 & $5.00 \mathrm{E}-05$ \\
\hline OS05G0472400 & Zinc/iron permease family protein (ZIP) & -2.158 & 5.00E-05 & -2.688 & 5.00E-05 & -2.677 & 5.00E-05 \\
\hline OSO3G0811900 & ADP-ribosylation factor 1-like (ARF1) & -0.200 & - & -1.043 & $5.00 \mathrm{E}-04$ & -0.706 & - \\
\hline OSO1G0265100 & ADP-ribosylation factor 2-like (ARF2) & -0.313 & - & -1.036 & $5.00 \mathrm{E}-04$ & -0.636 & - \\
\hline OS01G0667600 & Ras-related protein RABA1f (RabGTPase) & -2.127 & 5.00E-05 & -1.421 & $5.00 \mathrm{E}-04$ & -0.173 & - \\
\hline OS08G0525000 & Ras-related protein RABA5c (RabGTPase) & -0.951 & - & -1.030 & $5.00 \mathrm{E}-05$ & -0.294 & - \\
\hline OS03G0843100 & ras-related protein RABA2a (RabGTPase) & -1.122 & $5.00 \mathrm{E}-05$ & -1.490 & $5.00 \mathrm{E}-05$ & -1.134 & 5.00E-05 \\
\hline OS09G0500900 & $\begin{array}{l}\text { Ferric reductase transmembrane domain } \\
\text { containing protein (FR) }\end{array}$ & 0.695 & - & 1.032 & 0.021 & 0.968 & - \\
\hline OS04G0538400 & Vacuolar iron transporter2 (VIT2) & 3.313 & 5.00E-05 & 1.504 & $5.00 \mathrm{E}-05$ & 5.142 & $5.00 \mathrm{E}-05$ \\
\hline OS09G0396900 & Vacuolar iron transporter 1.2 (VIT1.2) & 3.857 & $5.00 \mathrm{E}-05$ & 2.403 & $5.00 \mathrm{E}-05$ & 1.357 & $5.00 \mathrm{E}-05$ \\
\hline
\end{tabular}

Notes: The expression fold change (LP/Ck) FC $=2^{\text {Log2FC }}$ e.g., the expression fold change (LP/Ck) of $I R T$ in TJ981 roots FC $=2^{-2.683}=0.156$. "-------" represents that due to FC $\leq 2$ or $\geq 0.5$, the $P$-Value was not given. $P$-Value $\leq 0.05$ (or $\leq 0.01$ ) represent that the difference reached significant (or very significant) levels, respectively 


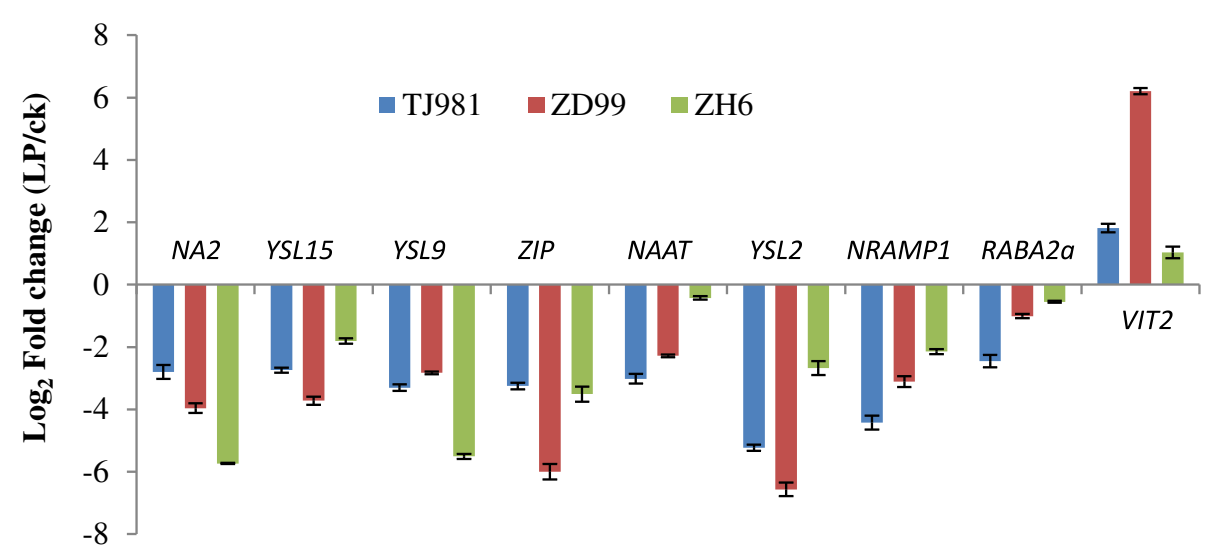

Fig. 4 Transcriptional level of the differentially expressed genes verified via qRT-PCR. Expression fold change (LP/ck) FC=2 Log2FC

prolonging, which may be called an adaptive response stage. Nevertheless, low Pi induced the transcription of VIT2 and the transcriptional induced degree of VIT2 first increased, then slightly decreased with extended low Pi treatment time.

\section{Intracellular distribution regulation of Fe}

Although low Pi promoted Fe accumulation in rice roots (Fig. 2), the intracellular distribution of Fe still remained regulated. The Fe content in the vacuole of low $\mathrm{Pi}$ treated root cells was significantly higher than that in ck (Fig. 6), which was consistent with the expression induction of the VITs gene under low Pi (Table 3, Fig. 5d). Furthermore, the Fe content in the cell wall was also higher than that in ck (Fig. 6). These results suggest that Fe was mainly stored in root vacuoles and cell walls under low Pi treatment, to alleviate the toxic effect of excessive $\mathrm{Fe}$ in the cytoplasm.

In summary, Fe homeostasis in rice roots was regulated by coordinated Fe uptake, transport, and intracellular distribution under low Pi. In contrast to Arabidopsis, Fe accumulation in rice roots did not inhibit the primary root growth under low-Pi stress.

Low-pi and low-Fe treatment leads to rice root lengthening As shown in Fig. 7, the low-Pi and low-Fe joint treatment $(\mathrm{LP}+\mathrm{LFe})$ did not cause the formation of Fe plaques on the rice root surface; however, the primary root lengths of TJ981 and ZD99 were significantly enhanced by either LP or LP + LFe treatments for $15 \mathrm{~d}$ compared to the control. This result indicates that the low Fe content in both medium and rice roots still resulted in the lengthening of the primary root, which was different in Arabidopsis.

\section{Low-pi promoted callose deposition in roots}

In Arabidopsis, Pi limitation triggered cell-specific apoplastic Fe and callose depositions in both meristem and elongation zone of primary roots. Here, we showed that Low-Pi promoted a small callose deposition in the elongation zone of primary roots in rice (Fig. 8). However, the relative amount of callose deposition was smaller compared to Arabidopsis.

Callose hydrolysis is catalyzed by $\beta-1-3$ glucanase. The transcriptome sequencing results of this experiment showed that the expression of the $\beta-1-3$ glucanase gene was induced by low-Pi in TJ981 (OSO3G0221500, $\log _{2} \mathrm{FC}=1.02$, $P$-value $=5.00 \mathrm{E}-05)$ and $\mathrm{ZH6}\left(\mathrm{OSO1G0631500}, \log _{2} \mathrm{FC}=\right.$ $1.10, P$-value $=0.00165)$ of roots. Furthermore, the $\beta-1-3$ glucanase activity in low-Pi treated rice roots was significantly higher than in control (Fig. 9). This result suggests that the callose deposition in low-Pi treated rice roots could be reversed by high expression of specific $\beta-1,3$ glucanase.

\section{Discussion}

This study confirmed that Pi deficiency induced root morphological remodeling in rice, which is a major developmental plant response to $\mathrm{Pi}$ deficiency and has been suggested to enhance the plant's adaptability to $\mathrm{Pi}$ deficiency. When cultured under Pi deficiency, some plants (such as Arabidopsis) decrease their primary root growth, while increasing the production of lateral roots [32]. However, unlike Arabidopsis, primary root lengthening happened during Pi deficiency treatment of rice $[33,34]$. The results of this experiment confirmed that low Pi stress promoted rice root expansion (especially primary root lengthening).

Phosphorus deficiency induced reddish brown Fe plaque formation on the surface of rice roots [26, 27]. The Fe plaques that formed on the root surface of rice seedlings can be regarded as a nutrient pool, contributing to the uptake of $\mathrm{P}$ and Fe. Our results confirmed that the reddish-brown Fe plaques formed after low Pi treatment for $1 \mathrm{~d}$ (Fig. 1a), and the thickness of the Fe plaque continuously increased with prolonged low Pi treatment time (Fig. $1 \mathrm{~b}$ and c). The 


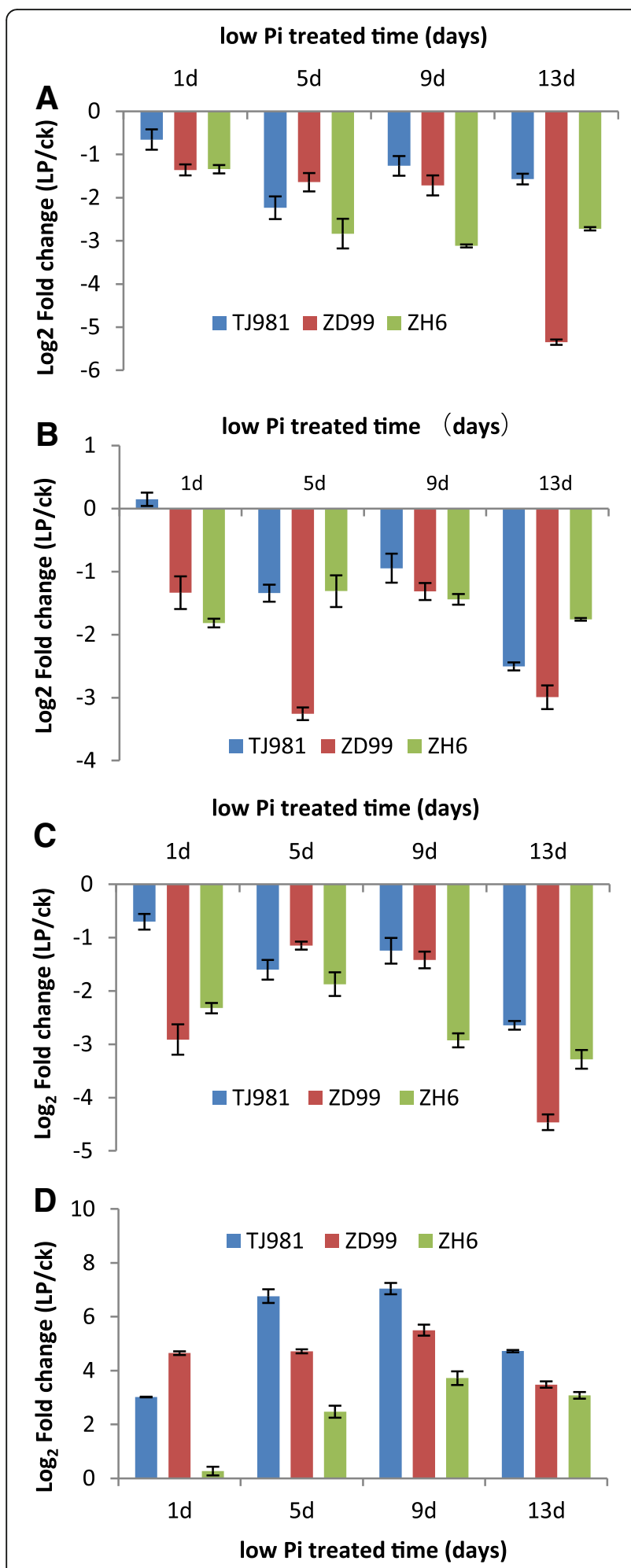

Fig. 5 Effect of low Pi treatment time on the transcriptional level of Fe uptake-related Key genes. a: OS03G0307200/NA2, b: OS02G0306401/ NAAT, c: OS02G0650300/YSL15, d: OS04G0538400NIT2. Expression fold change (LP/CK) FC $=2$ Log2FC formation of Fe plaques might be the result of the expression induction of $L P R 1$ genes.

When rice seedlings were treated with low $\mathrm{Pi}$, the $\mathrm{Fe}$ content in root surface (apoplast) and root symplast increased significantly due to formation of the Fe plaque (Figs. 2 and 3). It has been reported that, in Arabidopsis, $\mathrm{Pi}$ limitation triggered apoplastic Fe and callose deposition in the root meristem, and callose deposition inhibited symplastic communication in the root stem cell niche, which subsequently inhibited primary root growth [5]. Therefore, the antagonistic interactions of $\mathrm{Pi}$ and $\mathrm{Fe}$ availability controlled the primary root growth of Arabidopsis via meristem-specific callose deposition. To date, the role of $\mathrm{Fe}$ in the rice root morphological remodeling response to low Pi remains unclear. Although low Pi increased the Fe contents both on root surface (apoplast) and in root symplast in rice, primary root lengthening was observed in this study, implying that rice used different regulatory mechanisms for root morphological remodeling under low $\mathrm{Pi}$. Fe accumulation in rice roots did not inhibit primary root growth; in contrast, low $\mathrm{Pi}$ promoted primary root lengthening.

However, evidence for Fe-related toxicity during low Pi conditions is still missing. It has been proposed that the inhibited primary root growth under low Pi condition, might be caused by the toxic effect of excessive $\mathrm{Fe}$ [1]. Therefore, it is important to investigate how to regulate Fe homeostasis and alleviate the toxic effects of excessive accumulated $\mathrm{Fe}$ in low Pi treated rice roots. This experiment showed that, due to the down-regulated expression of Fe uptake-related key genes (including IRT, NAS, NAAT, YSLS, NRAMP1, ZIP, ARFs, and RABs) (Table 3, Fig. 10), the Fe uptake by mechanisms I, II, and III were all inhibited under low Pi stress. Furthermore, due to the up-regulated expression of the VIT2 and VIT1.2 genes (Fig. 10), Fe was stored more in the root vacuole and cell wall under low Pi stress. Therefore, Fe homeostasis in the rice root was appropriately controlled by Fe uptake, transport, and intracellular distribution. Consequently, $\mathrm{Fe}$ accumulation in the rice root symplast was insufficient to inhibit primary root growth under low-Pi stress. Moreover, LP + LFe treatment still induced primary root lengthening compared to control treatment. Consequently, Fe does not play an important role in rice root morphological remodeling under low $\mathrm{Pi}$.

One of the toxic effects of Fe accumulation in low $\mathrm{Pi}$ treated rice roots was the triggering of callose deposition in the root meristem. Our experiment showed that a small amount of callose was deposited in the elongation zone of rice primary roots. However, the relative amount of callose deposition was small compared to that in Arabidopsis, which may consequently not be sufficient to interfere with intercellular communication. The reason for callose deposition under control conditions might be 


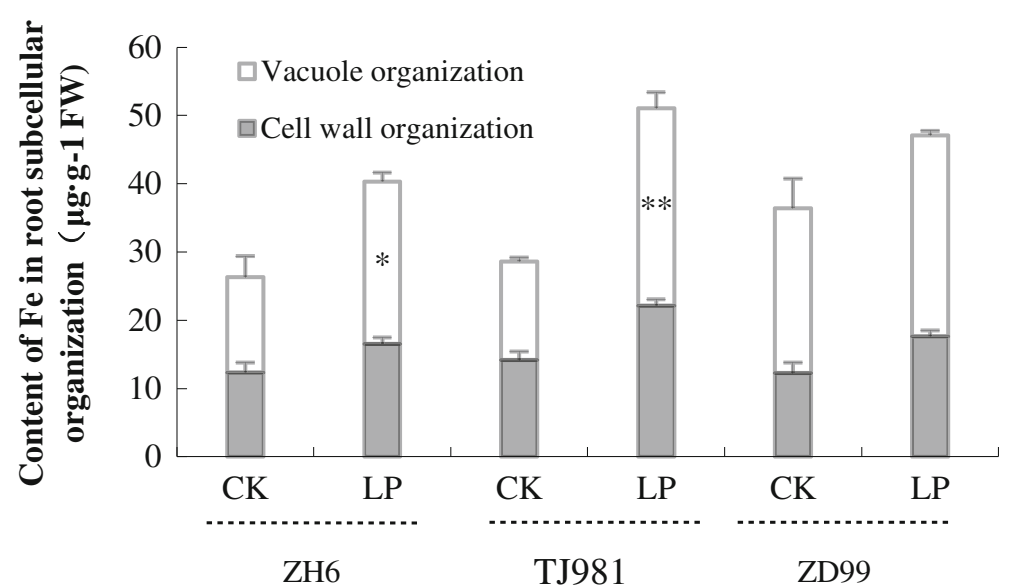

Fig. 6 Effect of low Pi on the Fe content in subcellular organelles of rice root cells. Notes: ${ }^{*}$ indicates significant difference $(P \leq 0.05)$, ** indicates extremely significant difference $(P \leq 0.01)$

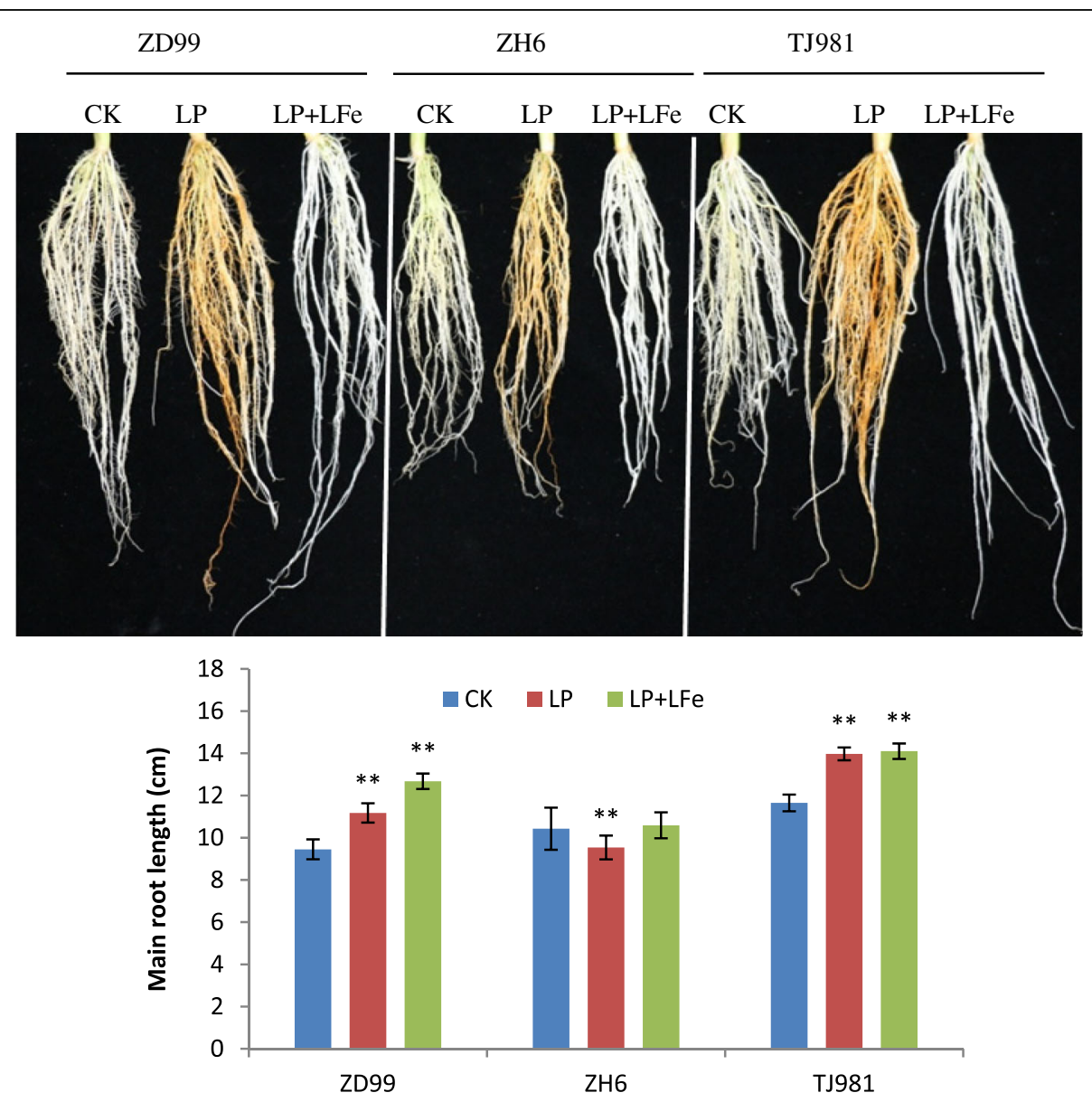

Fig. 7 Effect of low-Pi and low-Fe on rice root length. Notes: ** indicates extremely significant difference $(P \leq 0.01)$ 


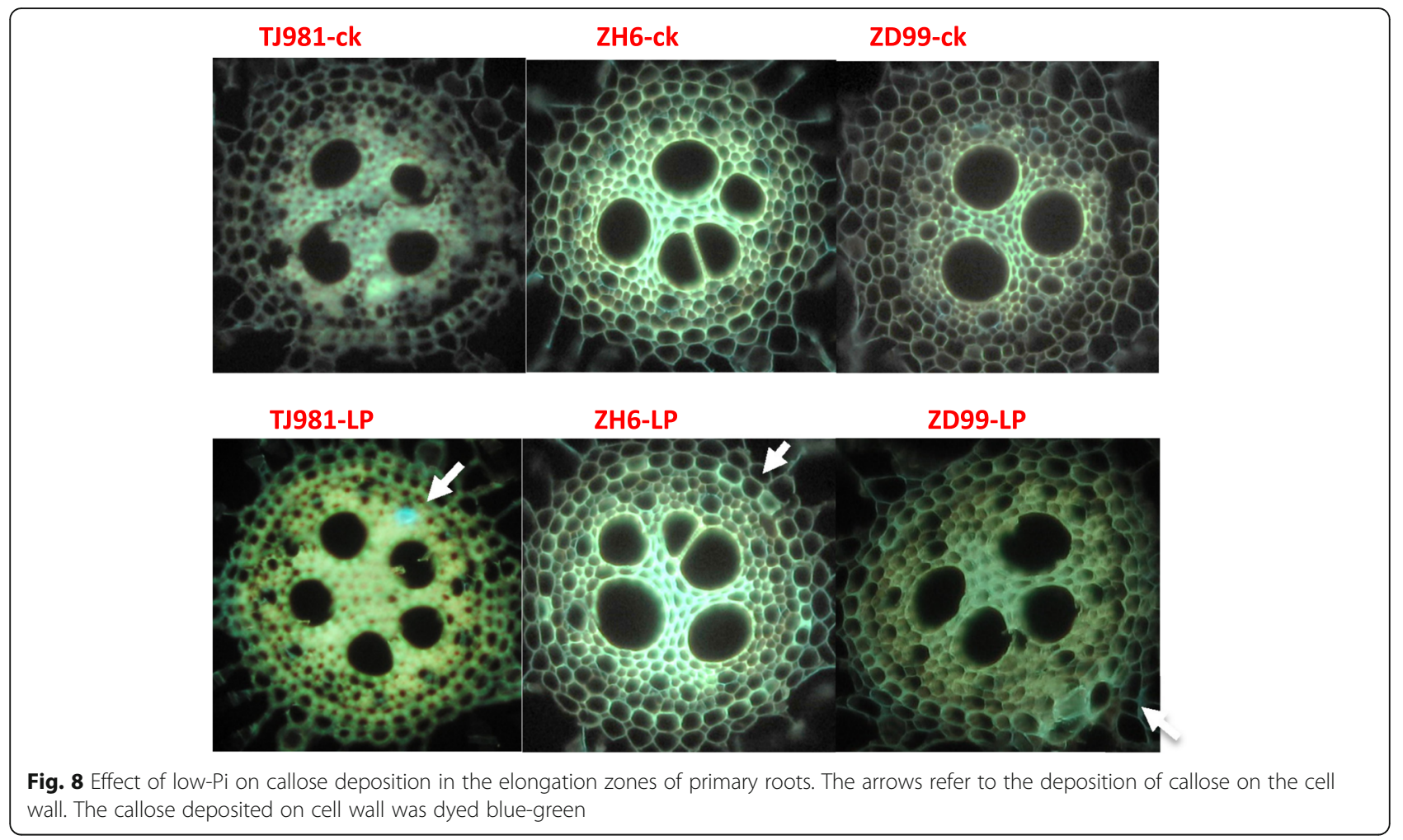

the expression induction and increased activity of $\beta-1-3$ glucanase in low Pi treated rice roots.

In summary, because Fe homeostasis in rice roots is appropriately controlled by the expression regulation of Fe uptake, transport, and intracellular distribution related genes, and because callose deposition in the cell wall is also controlled by expression induction and increased activity of $\beta-1-3$ glucanase, Fe only plays a small role in rice root morphological remodeling under low $\mathrm{Pi}$. In contrast, low Pi promoted primary root lengthening.

\section{Conclusions}

Pi deficiency induces root morphological remodeling in plants. This study confirmed that low Pi caused Fe plaque formation on the root surface and promoted primary root lengthening of rice. Fe uptake mechanisms I, II, and III in rice roots were all inhibited by down-regulated expression of Fe uptake-related key genes. Fe was increasingly stored in both root vacuoles and cell walls due to the up-regulated expression of the VITs gene and callose deposition in the cell wall was inhibited by induced expression

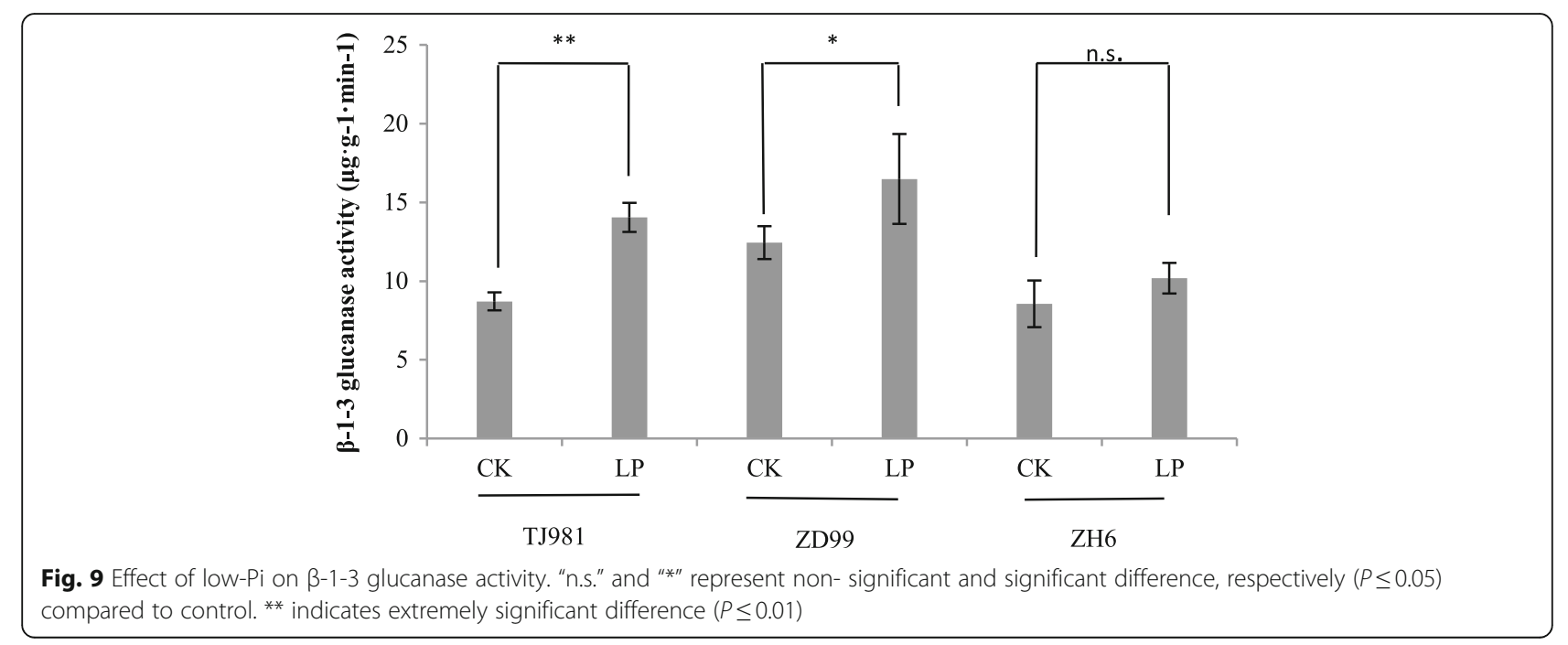




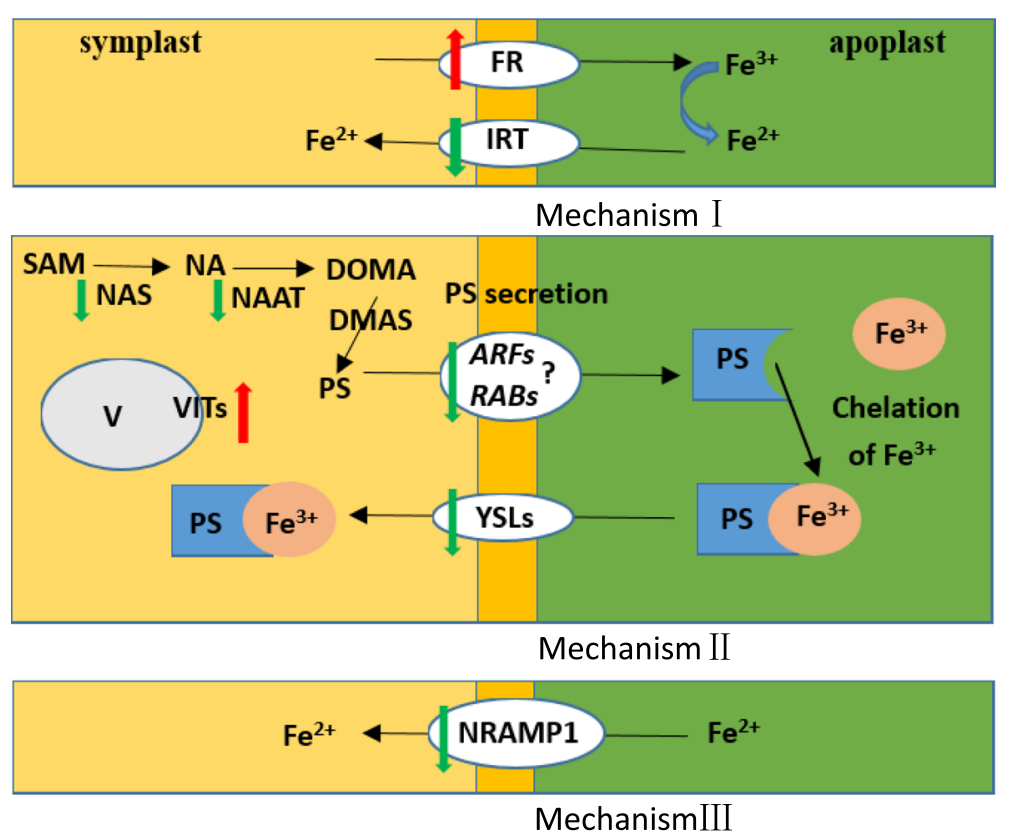

Fig. 10 Fe uptake strategy for plants and effects of low Pi on the expression of key genes involved in Fe uptake and distribution in rice roots. The green arrows indicate the down-regulated expression of corresponding genes, while the red arrow indicates up-regulated expression of corresponding genes; $\vee V$ represents the vacuole

and increased activity of $\beta-1-3$ glucanase. We also found that low Pi and low Fe treatment still caused primary root lengthening. All these results suggest that caused by the homeostasis of $\mathrm{Fe}$ and callose in rice roots treated to low $\mathrm{Pi}$, Fe does not play an important role in rice root morphological remodeling under low $\mathrm{Pi}$. In contrast, low Pi enhances primary root lengthening. However, the mechanism of low Pi promoting root length still remains unknown and it is significant to further elucidate the underlying mechanism.

\section{Methods}

\section{Plant materials}

Informed by our previous research results, three following rice cultivars were selected as test materials: TongJing 981 (TJ981), ZhengHan 6 (ZH6), and ZhenDao 99 (ZD99) corresponding to the primary root lengthening type, phosphorus efficient uptake and utilization type, and intermediate type rice cultivar response to low $\mathrm{Pi}$, respectively.

\section{Rice seedling culture and treatment}

Plump rice seeds were selected and sterilized via $10 \%$ $\mathrm{H}_{2} \mathrm{O}_{2}$ for $30 \mathrm{~min}$. After washing with deionized water, the seeds were placed in a Petri dish $(17 \mathrm{~cm})$, filled with deionized water to accelerate germination at $32{ }^{\circ} \mathrm{C}$. The germinating seeds were selected and placed into 96-well plastic plates. Then, the plates were placed in plastic boxes and complete nutrient solution of the International Rice
Research Institute [containing: $1.45 \mathrm{mM} \mathrm{NH}_{4} \mathrm{NO}_{3}, 0.323 \mathrm{mM}$ $\mathrm{NaH}_{2} \mathrm{PO}_{4} \cdot 2 \mathrm{H}_{2} \mathrm{O}, 0.512 \mathrm{mM} \mathrm{K} \mathrm{SO}_{4}, 0.998 \mathrm{mM} \mathrm{CaCl}$, $1.643 \mathrm{mM} \mathrm{MgSO}{ }_{4} \cdot 7 \mathrm{H}_{2} \mathrm{O}, 9.1 \mu \mathrm{M} \mathrm{MnCl}_{2} \cdot 4 \mathrm{H}_{2} \mathrm{O}, 0.075 \mu \mathrm{M}$ $\left(\mathrm{NH}_{4}\right)_{6} \mathrm{Mo}_{7} \mathrm{O}_{24} \cdot 4 \mathrm{H}_{2} \mathrm{O}, 18.882 \mu \mathrm{M} \mathrm{H}_{3} \mathrm{BO}_{3}, 0.152 \mu \mathrm{M} \mathrm{ZnSO}$ . $7 \mathrm{H}_{2} \mathrm{O}, 0.155 \mu \mathrm{M} \mathrm{CuSO}{ }_{4} \cdot 5 \mathrm{H}_{2} \mathrm{O}, 0.036 \mathrm{mM} \mathrm{FeCl}_{3} \cdot 6 \mathrm{H}_{2} \mathrm{O}$, and $0.031 \mathrm{mM} \mathrm{Na} \mathrm{EDTA}_{2} \cdot 2 \mathrm{H}_{2} \mathrm{O}, 0.071 \mathrm{mM}$ Citric acid monohydrate, and $500 \mathrm{ml}$ of concentrated sulfuric acid were added every $10 \mathrm{~L} ;(\mathrm{pH}=5.4)]$ was added. When the seedlings had grown to the 3-leaf stage, healthy seedlings were chosen and cultured with either normal nutrient solution (CK), low Pi (LP), or low Fe (LFe) nutrient solution. The Pi concentration of LP/CK was $1 / 25$, while the Fe concentration of LFe/CK was $1 / 20$. Each treatment contained six biological replicates. The seedlings were further cultured in an artificial climate chamber under controlled conditions (14-h photoperiod, $75 \%$ relative humidity, and $32 / 27{ }^{\circ} \mathrm{C}$ day/night regime). The solution was changed daily and the $\mathrm{pH}$ was adjusted to about 5.1. Rice seedlings were sampled after treatment durations of 1 to 30 days.

\section{Extraction of DCB-Fe from the rice root surface}

$\mathrm{DCB}-\mathrm{Fe}$ is a general term for both adsorption and precipitation of $\mathrm{Fe}$ on the root surface. DCB-Fe was measured via DCB (dithionite-citrate-bicarbonate) extraction method [35]. Briefly, after low Pi treatment for $15 \mathrm{~d}$, the rice roots were sampled and soaked overnight using tap water. After repeated washing with deionized water, the root surface moisture was absorbed by absorbent paper and the roots were placed in $150 \mathrm{ml}$ triangular flasks. 
The DCB extraction solution (consisting of: $40 \mathrm{ml}$ of $0.3 \mathrm{~mol} / \mathrm{L} \quad \mathrm{Na}_{3} \mathrm{C}_{6} \mathrm{H}_{5} \mathrm{O}_{7} \cdot 2 \mathrm{H}_{2} \mathrm{O}, 5.0 \mathrm{ml}$ of $1.0 \mathrm{~mol} / \mathrm{L}$ $\mathrm{NaHCO}_{3}$, and $3.0 \mathrm{~g} \mathrm{Na}_{2} \mathrm{~S}_{2} \mathrm{O}_{4}$ ) was added to triangular flasks, and then oscillated on a $280 \mathrm{x}$ g shaking table for $3 \mathrm{~h}$ at $25^{\circ} \mathrm{C}$. The solution was filtered into $100 \mathrm{ml}$ volumetric flasks at constant volumes. DCB-Fe content (or iron plaque thickness) was verified via the iron content of the per unit dry weight of roots.

\section{Digestion of rice roots}

After iron plaque removal via the $\mathrm{DCB}$ extraction method, the roots were repeatedly rinsed with deionized water, dried in the oven at $70-80{ }^{\circ} \mathrm{C}$, and ground to a fine powder in a ceramic mortar. Then, $0.5 \mathrm{~g}$ root powder was weighed, and both $5 \mathrm{ml}$ concentrated nitric acid and $3 \mathrm{ml}$ deionized water were added. After $\mathrm{H}_{2} \mathrm{O}_{2}$ addition (two drops), the root powder was digested in a high-pressure closed microwave digestion instrument (MARS 6, CEM, USA). The digestion solution was transferred to a $50 \mathrm{ml}$ volumetric flask at constant volume.

\section{Subcellular structure separation}

After iron plaque removal, $1.0 \mathrm{~g}$ roots were weighed and placed in a pre-cooling mortar. $10 \mathrm{~mL}$ homogenate (consisting of: $0.25 \mathrm{~mol} / \mathrm{L}$ sucrose, $50 \mathrm{mmol} / \mathrm{L}$ Tris-maleate buffer $(\mathrm{pH}=7.8), 1 \mathrm{mmol} / \mathrm{L} \mathrm{MgCl}_{2}$ and $10 \mathrm{mmol} / \mathrm{L}$ cysteine) were added to the mortar. The roots were ground to a fine homogenate, which was then transferred into a $50 \mathrm{~mL}$ centrifuge tube, and centrifuged using a high-speed refrigerated centrifuge at $1000 \mathrm{x}$ g for $2 \mathrm{~min}$ at $4{ }^{\circ} \mathrm{C}$. The precipitation at the bottom was collected for the cell wall component. The supernatant was further centrifuged at $12000 \mathrm{x} \mathrm{g}$ for $30 \mathrm{~min}$ at $4{ }^{\circ} \mathrm{C}$. The fragments on the bottom were collected for evaluation of the organelle composition. The supernatant formed the vacuolar component (consisting of vacuole and cytoplasm $\mathrm{Fe}$ ).

\section{Determination of iron content}

The contents of DCB-Fe, Fe in roots, and subcellular Fe (consisting of cell wall, organelle, and vacuolar components) were determined via plasma-atomic emission spectrometry (iCAP-6300, Thermo Fisher SCIENTIFIC, USA).

\section{Observation of callose deposition}

To measure callose deposition, the method of frozen section with aniline blue fluorescent staining was used [36]. Briefly, $10 \mathrm{~mm}$ rice root tips were sampled and a $5 \mathrm{~mm}$ subparagraph was cut out. The root tips were immersed in $10 \%$ glycerin. After pumping gas for $15 \mathrm{~min}$, the root tips were embedded, fixed, and cut into $15 \mu \mathrm{m}$ slices using a Leica CM 1900 frozen microtome. The sections were placed on a slide and soaked in $95 \%$ ethanol solution overnight; then, soaked in phosphate buffer $(1 / 15 \mathrm{~mol} / \mathrm{L}, \mathrm{pH}=7.0)$ for $30 \mathrm{~min}$. The sections were dyed in $0.05 \%$ aniline blue for $60 \mathrm{~min}$. The deposited callose was observed with an OlympusBX51 fluorescence microscope, excited by ultraviolet light.

\section{Determination of $\beta-1-3$ glucanase activity}

Determination of $\beta-1-3$ glucanase activity was conducted in accordance with Zhang et al. [37]; however, a slight change was implemented: $0.5 \mathrm{~g}$ roots were weighed and placed in a pre-cooled mortar. $5.5 \mathrm{~mL}$ sodium acetate buffer $(0.05 \mathrm{~mol} / \mathrm{L}, \mathrm{pH}=5.0)$ were added to the mortar. The roots were ground to a homogenate, which was then transferred into a $10 \mathrm{~mL}$ centrifuge tube and centrifuged at $15000 \mathrm{r} / \mathrm{min}$ for $15 \mathrm{~min}$ at $4{ }^{\circ} \mathrm{C}$. The supernatant was used as enzyme extraction. The enzyme extraction was heated in a water bath at $100{ }^{\circ} \mathrm{C}$ for $10 \mathrm{~min}$, which was used as control. $100 \mu \mathrm{l}$ Okam solution $(1 \mathrm{mg} / \mathrm{mL})$ and $100 \mu \mathrm{l}$ enzyme extraction was added to a $5 \mathrm{ml}$ centrifuge tube, and heated in a water bath at $37{ }^{\circ} \mathrm{C}$ for $30 \mathrm{~min}$. Then, $1 \mathrm{ml} \mathrm{DNS} \mathrm{solu-}$ tion was added to terminate the reaction. The reaction solution was placed in a boiling water bath for $5 \mathrm{~min}$ of coloration. After cooling to room temperature, the amount of glucose was measured via colorimetry at $540 \mathrm{~nm}$.

\section{Transcriptome sequencing \\ RNA library construction and sequencing}

For mRNA library construction and deep sequencing, RNA samples were prepared via the TruSeq RNA Sample Preparation Kit according to the manufacture's protocol [38]. Briefly, the poly-A containing mRNA molecules were purified with $3 \mu \mathrm{g}$ of total RNA via poly-T oligo-attached magnetic beads. Cleaved RNA fragments were reversely transcribed into first strand cDNA using random hexamers, followed by second-strand cDNA synthesis using DNA polymerase I and RNase H. cDNA fragments were purified, end blunted, 'A' tailed, and adaptor ligated. PCR was used to selectively enrich DNA fragments with adapter molecules on both ends and to amplify the amount of DNA in the library. The number of PCR cycles was minimized to avoid skewing representation of the library [39]. The resulting library was qualified via the Agilent 2100 bioanalyzer and quantified via both Qubit and qPCR. The produced libraries were sequenced on the HiSeq 2500 platform.

\section{Data analysis workflow of transcriptional profiling}

Information on the reference gene set and corresponding annotations: Oryza indica gene set referred to ENSEMBL (ftp://ftp.ensemblgenomes.org/pub/-release-23/plants/fasta/ oryza_indica/cdna/Oryza_indica.ASM465v1.23.cdna.all.fa.gz).

Analysis of the gene expression profile: sequencing reads were mapped onto the reference gene set via Bowtie1 software (Bowtie parameter: -v 3 -all -best -strata). A Perl script program was utilized to process the mapping results and to generate a gene expression profile. 
Table 4 Primers for real-time quantitative PCR

\begin{tabular}{lllll}
\hline Gene Symbol & Sense primer (5'-3') & Reverse primer (5'-3') & Product length \\
\hline OS07G0258400 & TाTGGGTATTTGATTGGC & CTTCTGGAATATCGGAAGCA & 180 & 55.0054 .94 \\
OS05G0472400 & TाTCTTGCTCTAAGCAGTGT & CCACAAAAAGTCTACACCCA & 169 & 54.9155 .49 \\
OS04G0542200 & CAAGACGGGACATCTAACAT & AGGCACTGTAGAACAAGAAG & 116 & 54.8755 .01 \\
OS03G0843100 & ATTGGATTGCTTGAGGTGAT & GAAGCGGCTGTACTATGTTA & 130 & 54.9755 .00 \\
OS03G0307200 & TGAGTGCGTGCATAGTAATC & TCATCCACACAACAAGAACA & 122 & 55.6755 .12 \\
OS02G0306401 & GTTGCCTTTATGGCCTTT & CACTATATATGGCTCGCCTC & 105 & 54.9955 .01 \\
OS02G0650300 & GAAAGCAGCATGACAAGTT & AAAAACGACTGCAAAAGGAG & 127 & 55.0855 .02 \\
OS02G0649900 & TCCTTAACTTGCTTCCACTC & GGAAGAAGCTCCATAAGAGG & 183 & 54.9954 .93 \\
OS04G0538400 & AATAATCAAGGGTTGTGCT & AACCATTACACTACACCCC & 142 & 54.8854 .94 \\
\hline
\end{tabular}

\section{Analysis of differentially expressed genes}

According to credibility interval approaches that had been reported for the analysis of SAGE data5 [40], the edgeR6 program was used to identify differentially expressed mRNAs based on their relative quantities, which were reflected by individual gene reads [41]. The method used empirical Bayes estimation and exact tests based on negative binomial distribution. Genes with a $P$ value $\leq 0.01$ and an expression ratio $\geq 2$ (up-regulation) or expression ratio $\leq 0.5$ (down-regulation) were recognized as significantly differentially expressed genes between both samples.

\section{Real time fluorescent quantitative PCR (qRT-PCR) verification} Primer design and synthesis

Nine differentially expressed Fe uptake and distribution-related genes detected via RNA-seq were selected. cDNA sequences of these genes were searched in a NCBI database. Primers (see Table 4) were designed with Primer 5.0 software according to CDS and then synthesized by Invitrogen Co. Ltd., USA.

\section{Total RNA isolation}

After the rice seedlings had been treated by low Pi for 1 , 5, 9, 13 days, roots were harvested to extract total RNA using the RNAprep pureplant kit (Tiangen, Beijing, China), according to the manufacturer's protocol.

\section{First-strand CDNA synthesis}

First-strand cDNA was synthesized by reverse transcribing $5 \mu \mathrm{L}$ of total RNA in a final reaction volume of $20 \mu \mathrm{L}$ using TIANScriptRT kit (Tiangen, Beijing, China) according to the manufacturer's instructions. The cDNA concentration was determined using an Eppendorf Biophotometer. According to the cDNA concentration, the volumes of the products of reverse transcription were regulated to ensure identical cDNA concentration in each treatment.

\section{Real-time quantitative PCR detection}

Real-time quantitative PCR analysis was conducted using the Real-Time PCR System (CFX96 Touch, Bio-Rad,
USA). The SYBR Premix Ex Taq (TaKaRa) kit was used, using ubiquitin 5 (UBQ 5) gene as reference gene [42]. Amplification was done in parallel with the target gene allowing normalization of gene expression, while providing quantification. The reaction procedure was as follows: Pre-denaturation at $95{ }^{\circ} \mathrm{C}$ for $30 \mathrm{~s}$, followed by 40 cycles of: denaturation at $95{ }^{\circ} \mathrm{C}$ for $5 \mathrm{~s}$, annealing at $55{ }^{\circ} \mathrm{C}$ for $30 \mathrm{~s}$, and extension at $70{ }^{\circ} \mathrm{C}$ for $30 \mathrm{~s}$. The relative expressed quantitation (RQ) was calculated via the $2^{-\Delta \Delta C T}$ method [43].

\section{Data statistical analysis}

All data were analyzed with Excel 2003 and SPSS 12.0 using AVOV at a significance level of $P \leq 0.05$.

\section{Abbreviations}

ARF: ADP-ribosylation factor; CK: Normal nutrient solution; DCB: Dithionitecitrate-bicarbonate; DMAS: Deoxymugineicacid synthase; DNS: 3,5-dinitrosalicylic acid colorimetry; DOMA: Deoxymugineic acid; FR: Ferric reductase transmembrane protein; FRO: Ferric reductase oxidase; IRT: The Fe ${ }^{2+}$ transporter; LFe: Low Fe; LP: Low Pi; NA: Nicotianamine; NAAT: Nicotianamine aminotransferase; NAS: Nicotianamine synthases; Pi: Phosphorus; PS: Phytosiderophores; qRT-PCR: Quantitative Real-time Polymerase Chain Reaction; RAM: Root apical meristem; SAM: S-adenosylmethionine; TJ981: TongJing 981; VIT2: Vacuolar iron transporter2 gene; ZD99: ZhenDao 99; ZH6: ZhengHan 6

\section{Acknowledgments}

A Project Funded by the Priority Academic Program Development of Jiangsu Higher Education Institutions (PAPD).

\section{Funding}

This research was supported by the Special Fund for Agro-Scientific Research in the Public Interest (No. 201103007) and the Priority Academic Program Development of Jiangsu Higher Education Institutions, China.

\section{Availability of data and materials}

The datasets generated and analysed during the current study are available from the corresponding author on reasonable request.

\section{Authors' contributions}

$\mathrm{GCL}$ conceived the study, edited the manuscript, and supervised the work. WYL participated in conceiving the project, provided financial support for the study, and supervised the work. DY carried out most experimentation, contributed to the design of the study, and drafted the manuscript. WZG carried out most transcriptome data analysis. RML and ZP prepared the rice seeds, grew rice plants, and performed low pi treatment. LZN and CS performed the qRT-PCR analysis. All authors reviewed and contributed to draft the manuscript. All authors read and approved the final manuscript. 


\section{Ethics approval and consent to participate}

Not applicable.

\section{Consent for publication}

Not applicable.

\section{Competing interests}

The authors declare that they have no competing interests.

\section{Publisher's Note}

Springer Nature remains neutral with regard to jurisdictional claims in published maps and institutional affiliations.

\section{Author details}

'Jiangsu Key Laboratory of Crop Genetics and Physiology/ Jiangsu Key Laboratory of Crop Cultivation and Physiology, Jiangsu Co-Innovation Center for Modern Production Technology of Grain Crops, Agricultural College of Yangzhou University, Yangzhou University, 88 Daxue South Road, Yangzhou 225009, People's Republic of China. ${ }^{2}$ College of Bioscience and Biotechnology, Yangzhou University, 88 Daxue South Road, Yangzhou 225009, People's Republic of China. ${ }^{3}$ College of Materials and chemical engineering, Bengbu University, 1866 Caoshan Road, Bengbu 233000, People's Republic of China.

\section{Received: 13 March 2018 Accepted: 16 October 2018} Published online: 04 December 2018

\section{References}

1. Ward JT, Lahner B, Yakubova E, Salt DE, Raghothama KG. The effect of iron on the primary root elongation of Arabidopsis during phosphate deficiency. Plant Physiol. 2008;147:1181-91.

2. Reymond M, Svistoonoff S, Loudet O, Nussaume L, Denos T. Identification of QTL controlling root growth response to phosphate starvation in Arabidopsis thaliana. Plant Cell Environ. 2006;29:115-25.

3. Svistoonoff S, Creff A, Reymond M, Sigoillot-Claude C, Ricaud L, Blanchet A, Nussaume L, Desnos T. Root tip contact with low-phosphate media reprograms plant root architecture. Nat Genet. 2007;39:792-6.

4. Ticconi CA, Lucero RD, Sakhonwasee S, Adamson AW, Creff A, Nussaume L, Desnos T, Abel S. ER-resident proteins PDR2 and LPR1 mediate the developmental response of root meristems to phosphate availability. Proc Natl Acad Sci U S A. 2009;106(33):14174-9.

5. Müller J, Toev T, Heisters M, Teller J, Moore KL, Hause G, Dinesh DC, BüRstenbinder K, Abel S. Iron-dependent Callose deposition adjusts root meristem maintenance to phosphate availability. Dev Cell. 2015;33:216-30.

6. Gutiérrez-Alanls D, Yong-Villalobos $L$, Jiménez-Sandoval P, Alatorre-Cobos F, Oropeza-Aburto A, Mora-Maclas J, Sánchez-Rodrĺguez F, Cruz-Ramĺrez A, Herrera-Estrella L. Phosphate starvation-dependent Iron mobilization induces CLE14 expression to trigger root meristem differentiation through CLV2/PEPR2 signaling. Dev Cell. 2017;41:555-70.

7. Xu HX, Weng XY, Yang Y. Effect of phosphorus deficiency on the photosynthetic characteristics of rice plants. Russ J Plant Physiol. 2007;54(6): 741-8.

8. Li YF, Luo AC, Hassan MJ, Wei XH. Effect of phosphorus deficiency on leaf photosynthesis and carbohydrates partitioning in two rice genotypes with contrasting low phosphorus susceptibility. Rice Sci. 2006;13(4):283-90.

9. Park MR, Baek S-H, de los Reyes BG, Yun SJ, Hasenstein KH. Transcriptome profiling characterizes phosphate deficiency effects on carbohydrate metabolism in rice leaves. J Plant Physiol. 2012;169(2):193-205.

10. Li LH, Liu C, Lian XM. Gene expression profiles in rice roots under low phosphorus stress. Plant Mol Biol. 2010;72(4-5):423-32.

11. Cao Y, Yan Y, Zhang F, Wang HD, Gu M, Wu XN, Sun SB, Xu GH. Fine characterization of $\mathrm{Os} \mathrm{PHO} 2$ knockout mutants reveals its key role in pi utilization in rice. J Plant Physiol. 2014;171(3-4):340-8.

12. Zhou J, Jiao FC, Wu ZC, Li YY, Wang XM, He XW, Zhong WQ, Wu P. OsPHR2 is involved in phosphate-starvation signaling and excessive phosphate accumulation in shoots of plants. Plant Physiol. 2008;146:1673-86.

13. Liu F, Wang ZY, Ren HY, Shen CJ, Li Y, Ling HQ, Wu CY, Lian XM, Wu P. OsSPX1 suppresses the function of OSPHR2 in the regulation of expression of OsPT2 and phosphate homeostasis in shoots of rice. Plant J. 2010;62(3): 508-17.
14. Wang C, Wei H, Ying YH, Li S, Secco D, Tyerman S, Whelan J, Shou HX. Functional characterization of the rice SPX-MFS family reveals a key role of OsSPX-MFS1 in controlling phosphate homeostasis in leaves. New Phytol. 2012;196:139-48.

15. Hou XL, Wu P, Jiao FC, Jia QJ, Chen HM, Yu J, Song XW, Yi KK. Regulation of the expression of OsIPS1 and OsIPS2 in rice via systemic and local pi signalling and hormones. Plant Cell Environ. 2005;28(3):353-64.

16. Zhang Q, Wang C, Tian J, Li K, Shou H. Identification of rice purple acid phosphatases related to phosphate starvation signalling. Plant Biol. 2011;13(1):7-15.

17. Wang ZY, Hu H, Huang HJ, Duan K, Wu ZC, Wu P. Regulation of OsSPX1 and OSSPX3 on expression of OSSPX domain genes and pi-starvation signaling in rice. J Integr Plant Biol. 2009;51(7):663-74.

18. Wasaki J, Yamamura T, Shinano T, Osaki M. Secreted acid phosphatase is expressed in cluster roots of lupin in response to phosphorus deficiency. Plant Soil. 2003;248(1-2):129-36.

19. Li JZ, Xie Y, Dai AY, Liu LF, Li ZC. Root and shoot traits responses to phosphorus deficiency and qtl analysis at seedling stage using introgression lines of rice. J Genet Genomics. 2009;36(3):173-83.

20. Shimizu A, Yanagihara S, Kawasaki S, Ikehashi H. Phosphorus deficiencyinduced root elongation and its qtl in rice (oryza sativa I.). Theor Appl Genet. 2004;109(7):1361-8.

21. Li HB, Xia M. Wu P. effect of phosphorus deficiency stress on rice lateral root growth and nutrient absorption. Acta Bot Sin. 2001;43(11):1154-60.

22. Shimizu A, Kato K, Komatsu A, Motomura K, Ikehashi H. Genetic analysis of root elongation induced by phosphorus deficiency in rice (oryza sativa l.): fine QTL mapping and multivariate analysis of related traits. Theor Appl Genet. 2008;117(6):987-96.

23. Chin JH, Gamuyao R, Dalid C, Bustamam M, Prasetiyono J, Moeljopawiro S, Wissuwa M, Heuer S. Developing rice with high yield under phosphorus deficiency: Pup1 sequence to application. Plant Physiol. 2011;156:1202-16.

24. Gamuyao R, Chin JH, Pariasca-Tanaka J, Pesaresi P, Catausan S, Dalid C, Slamet-Loedin I, Tecson-Mendoza EM, Wissuwa M, Heuer S. The protein kinase pstol 1 from traditional rice confers tolerance of phosphorus deficiency. Nature. 2012;488(7412):535-9.

25. Dai $X$, Wang $Y$, Zhang WH. OsWRKY74, a WRKY transcription factor, modulates tolerance to phosphate starvation in rice. J Exp Bot. 2016;67(3):947-60.

26. Liu WJ, Hu Y, Zhu YG, Gao RT, Zhao QL. The mechanisms of iron plaque formation on the surface of rice roots induced by phosphorus starvation. Plant Nutr Fertilizer Sci. 2008;14:22-7.

27. Fu YQ, Yang XJ, Wu DM, Shen H. Effect of phosphorus on reddish brown iron plaque on root surface of rice seedlings and their nutritional effects. Sci Agric Sin. 2014;47(6):1072-85.

28. Zheng LQ, Huang FL, Narsai R, Wu JJ, Giraud E, He F, Cheng LJ, Wang F, Wu P, Whelan J, Shou HX. Physiological and transcriptome analysis of iron and phosphorus interaction in rice seedlings. Plant Physiol. 2009;151:262-74.

29. Li F, Pan XH, Liu SY, Li MY, Yang FS. Effect of phosphorus deficiency stress on root morphology and nutrient absorption of Rice cultivars. Acta Agron Sin. 2004;30:438-42.

30. Marschner HV, Romheld V, Horst WJ, Martin P. Root-induced changes in the rhizosphere: importance for the mineral nutrition of plants. $Z$ Pflanzenemaehr Bodenk. 1986;149:441-56.

31. Ishimaru Y, Suzuki M, Tsukamoto T, Sukuki K, Nakazono M, Kobayashi T, Wada Y, Watanabe S, Matsuhashi S, Takahashi M. Rice plantstake up iron as an $\mathrm{Fe}^{3+}$-phytosiderophore and as Fe ${ }^{2+}$. Plant J. 2006;45(3):335-46.

32. Desnos T. Root branching responses to phosphate and nitrate. Curr Opin Plant Biol. 2008:11(1):82-7.

33. Wissuwa M, Gamat G, Ismail AM. Is root growth under phosphorus deficiency affected by source or sink limitations? J Exp Bot. 2005;56(417): 1943-50.

34. Panigrahy M, Nageswara Rao D, Sarla N. Molecular mechanisms in response to phosphate starvation in rice. Biotechnol Adv. 2009;27(4):389-97.

35. Taylor GJ, Crowder AA. Use of the DCB technique for extraction of hydrous iron oxides from roots of wetland plant. Am J Bot. 1983;70(8):1254-7.

36. Yang L, Chen JM, Zhang HQ, Zhang JF, He YP.Effects of Brown planthopper, Nilaparvata lugens(Stal) (Homoptera:Delphacidae). Feeding on Callose Deposition in Rice with Different Tolerance. Chin J Rice Sci,2013,27(6):624-32

37. Zhang DD, Yun XF, Bao YY, Qian C, Gao XM. Effects of extracts celery fresh root and rhizosphere area on the chitinase and bata 1,3-glucan engymes activity of cucumber leaf. J Inner Mongolia Agricultural University. 2013;34: $21-7$. 
38. Tao T, Zhao L, Lv YD, Chen JD, Hu Y, Zhang TZ, Zhou BL. Transcriptome sequencing and differential gene expression analysis of delayed gland morphogenesis in Gossypium australe during seed germination. PLoS One. 2013;8(9):e75323. https://doi.org/10.1371/journal.pone.0075323.

39. Gao J, Luo M, Zhu Y, He Y, Wang Q, Zhang C. Transcriptome sequencing and differential gene expression analysis in Viola yedoensis Makino (fam. Violaceae) responsive to cadmium (cd) pollution. Biochem Biophys Res Commun. 2015;459(1):60-5.

40. Robinson MD, Smyth GK. Small sample estimation of negative binomial dispersion with applications to SAGE data. Biostatistics. 2008;9(2):321-32.

41. Robinson MD, Oshlack A. A scaling normalization method for dierential expression analysis of RNA-seq data. Genome Biol. 2010;11:R25.

42. Jain M, Nijhawan A, Tyagi AK, Khurana JP. Validation of housekeeping genes as internal control for studying gene expression in rice by quantitative realtime PCR. Biochem Biophys Res Commun. 2006;345(2):646-51.

43. Livark KJ, Schmittgen TD. Analysis of relative gene expression data using realtime quantitative PCR and the 2- $\Delta \Delta C$ t method. Methods. 2001;25(4):402-8.

Ready to submit your research? Choose BMC and benefit from:

- fast, convenient online submission

- thorough peer review by experienced researchers in your field

- rapid publication on acceptance

- support for research data, including large and complex data types

- gold Open Access which fosters wider collaboration and increased citations

- maximum visibility for your research: over $100 \mathrm{M}$ website views per year

At $\mathrm{BMC}$, research is always in progress.

Learn more biomedcentral.com/submissions 